\title{
LO CEREMONIAL EN EL CONTEXTO DE LA VIDA SECULAR. ASENTAMIENTO URBANO DEL PERÍODO HORIZONTE tardío: Pueblo Viejo - Pucará, valle de Lurín
}

\author{
Manuel Lizárraga Ibáñez*
}

\begin{abstract}
Resumen
Los aspectos ceremoniales de la vida cotidiana no sólo se manifiestan dentro de zonas especializadas de culto (como plataformas o plazas), sino también dentro de áreas seculares de uso doméstico (dentro de viviendas). Las investigaciones en dos zonas funcionalmente distintas: 1) doméstica y 2) ceremonial; llevadas a cabo en Pueblo Viejo-Pucará, en el marco del Proyecto Arqueológico - Taller de Campo "Lomas de Lurín”, Convenio Cementos Lima S.A. - Pontificia Universidad Católica del Perú, bajo la dirección del Dr. Makowski; han identificado algunos eventos ceremoniales al interior de las unidades domésticas.

Los resultados de las excavaciones muestran que los comportamientos ceremoniales en ambas zonas no utilizan una "vajilla ceremonial" exclusiva, sino más bien, es la misma vajilla que dependiendo del contexto cumplía la doble función de ser utilitaria o ceremonial. Al parecer, los aspectos ceremoniales no representaban un mundo aparte (oposición sagrado/profano: Durkheim [1912] 1993) sino, todo lo contrario, eran considerados como parte de la vida cotidiana, en donde su existencia dependía de las obligaciones y rituales de la misma sociedad.
\end{abstract}

Palabras Clave

Inca, período Horizonte Tardío, arqueología doméstica, aspectos ceremoniales.

\begin{abstract}
The ceremonial aspects within secular life not only occur inside cult specialized zones (as platforms or plazas), instead of this, they can occur inside secular areas of domestic use too (inside residences). The investigations in two functionally distinct zones: domestic and ceremonial; undertook in Pueblo ViejoPucará site, which part of the "Lomas de Lurín" Archaeological Field School Project, directed by Dr. Krzysztof Makowski, have identified some ceremonial events inside households.

The excavation results showed that ceremonial performances found in both zones not are using an exclusive "ceremonial vessels complex", and rather, the same vessels complex that depending on the context perform a double function to be utilitarian or ceremonial. In fact, the ceremonial aspects were not representing a separate worlds (sacred/profane opposition: Durkeim [1912] 1993) but, instead, they were considered to be a part of the daily life, where their existence were depended on the obligations and rituals of the same society.
\end{abstract}

Keywords

Inca, Late Horizon period, household archaeology, ceremonial aspects.

* Proyecto Arqueológico Huaca Pucllana, Licenciado en Arqueología.

Correo electrónico: paliveomo@hotmail.com 
A raíz de una comparación no necesariamente válida en la sociedad occidental del siglo XIX, muchos antropólogos plantearon la existencia de una rígida dicotomía entre lo secular y lo religioso en la vida diaria de toda sociedad compleja. Sin embargo, el avance de estudios antropológicos y arqueológicos sobre el mundo ceremonial andino (Millones y Onuki 1994) demuestra la falacia de este planteamiento. Precisamente, nuestras investigaciones en el marco del Proyecto Arqueológico-Taller de Campo "Lomas de Lurín” se encuentran en esa dirección. Así, a solicitud del director del proyecto, se trabajaron dos unidades de excavación en el asentamiento del periodo Horizonte Tardío: Pueblo Viejo-Pucará, valle de Lurín, localizadas, en dos zonas funcionalmente distintas (zona doméstica y zona ceremonial).

\section{UBICACIÓN Y CARACTERÍSTICAS DEL SITIO}

El asentamiento urbano Pueblo Viejo-Pucará se ubica en el sistema de quebradas laterales que desembocan en la margen izquierda del río Lurín (fig.1). Si se le compara a otros sitios del Periodo Horizonte Tardío, Pueblo Viejo-Pucará parece haber sido el asentamiento de mayor importancia en la zona de lomas, quizás el asentamiento principal de los Caringas de Huarochirí, cuyos señores administraban la margen izquierda del valle con la extensa área de lomas que cubre hasta el vecino valle de Chilca (Makowski 2002, Makowski y Vega-Centeno 2004).

El asentamiento se compone de cuatro agrupaciones de vivienda (fig.2), dos residencias de elite de características palaciegas (estructuras de diseño ortogonal con patios internos y amplios espacios de almacenamiento), además de un templo en la parte alta. La distribución espacial de estos conjuntos muestra que cada una de las dos residencias palaciegas estuvo asociada a dos aglomeraciones de vivienda. Así, una de ellas, la más monumental, se ubica en el fondo de una de las quebradas tributarias de la quebrada
Pueblo Viejo; mientras que la otra, se encuentra en la parte alta del sitio, en las cimas desde las que se domina visualmente la costa, la entrada al valle y el acceso al santuario de Pachacamac desde el Sur.

Cabe mencionar que esta organización espacial del asentamiento evoca probablemente a una organización social frecuente en la sierra: dos mitades, alta y baja, cada una con sus respectivos barrios (iayllus comunes?), además de la gran residencia de carácter palaciego con dependencias y estructuras domésticas semi-independientes y asociadas entre sí, será esto acaso la iresidencia del quinto ayllu gobernante? (Makowski et al. 2007 e.p.).

En base a sus características arquitectónicas: residencias con mampostería de piedra similar a la tradición Huarochirí, depósitos alargados de dos pisos, aglomeraciones de vivienda distribuidas en las cimas intermedias y organización modular de los espacios domésticos (ver más adelante), además de los comportamientos funerarios y la presencia del componente serrano dentro del repertorio de estilos de cerámica; Pueblo Viejo-Pucará estuvo estrechamente emparentado con la sierra de Yauyos, como un asentamiento construido y habitado por los pobladores serranos desplazados hacia la costa desde las alturas del valle como mitimaes (Makowski et al. 2007 e.p.).

El sitio arqueológico de Pueblo Viejo - Pucará fue construido íntegramente durante el periodo Horizonte Tardío (aprox. 1470-1533 d.C.). Las excavaciones demostraron la existencia de fragmentos diagnósticos del periodo Horizonte Tardío (figs.3a y 3b) (vg. fragmentos de aríbalos Cuzco Policromo de imitación local -Inca Costeño- y botellas de indudable manufactura Chimú-Inca) en todas las unidades estratigráficas, incluyendo la primera sub-fase de ocupación -sobre estéril-, confirmando que el asentamiento fue edificado durante este periodo. Hasta el presente, no se han encontrado 


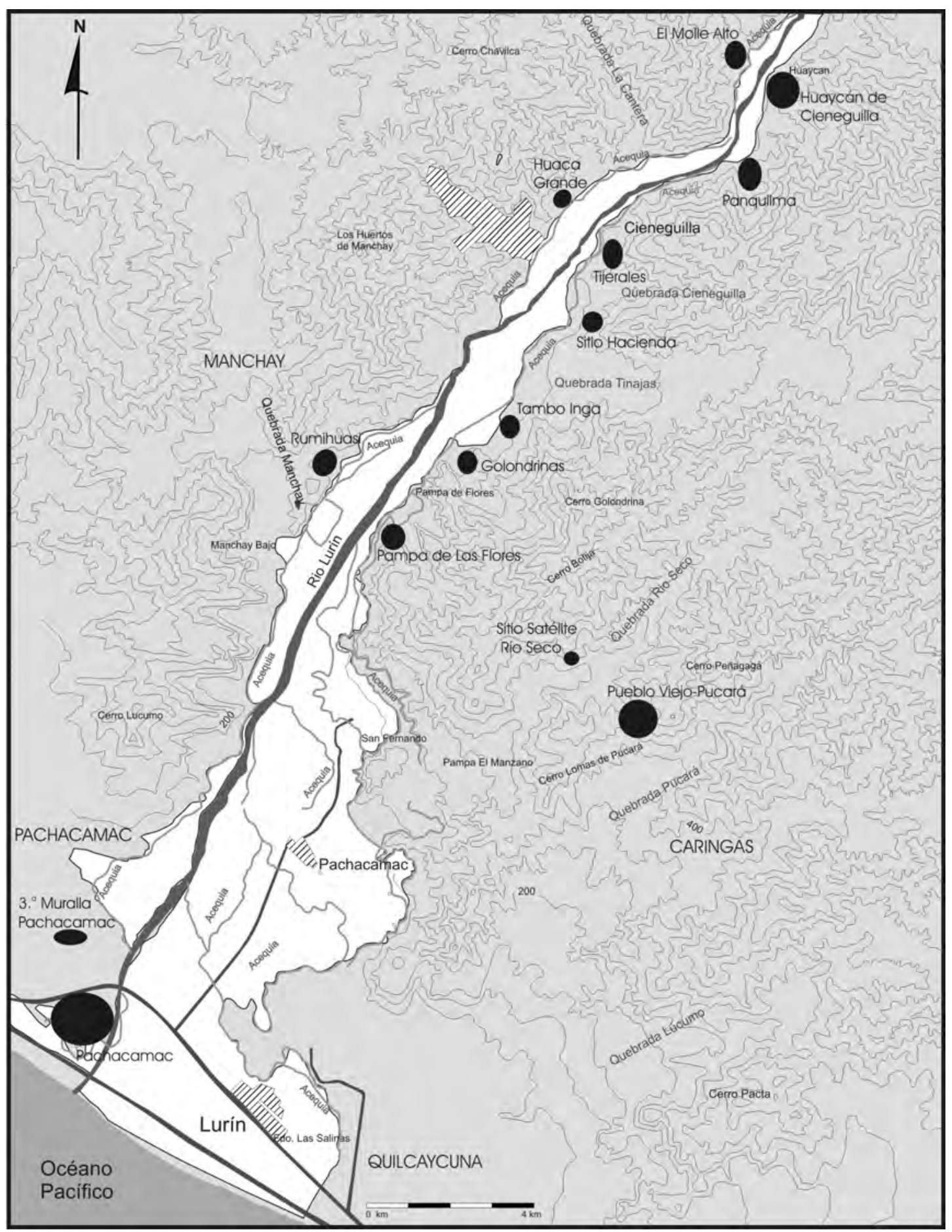

Figura 1. Ubicación de Pueblo Viejo-Pucará y otros asentamientos del Periodo Horizonte Tardío en el valle de Lurín (Dib.: M. Lizárraga). 


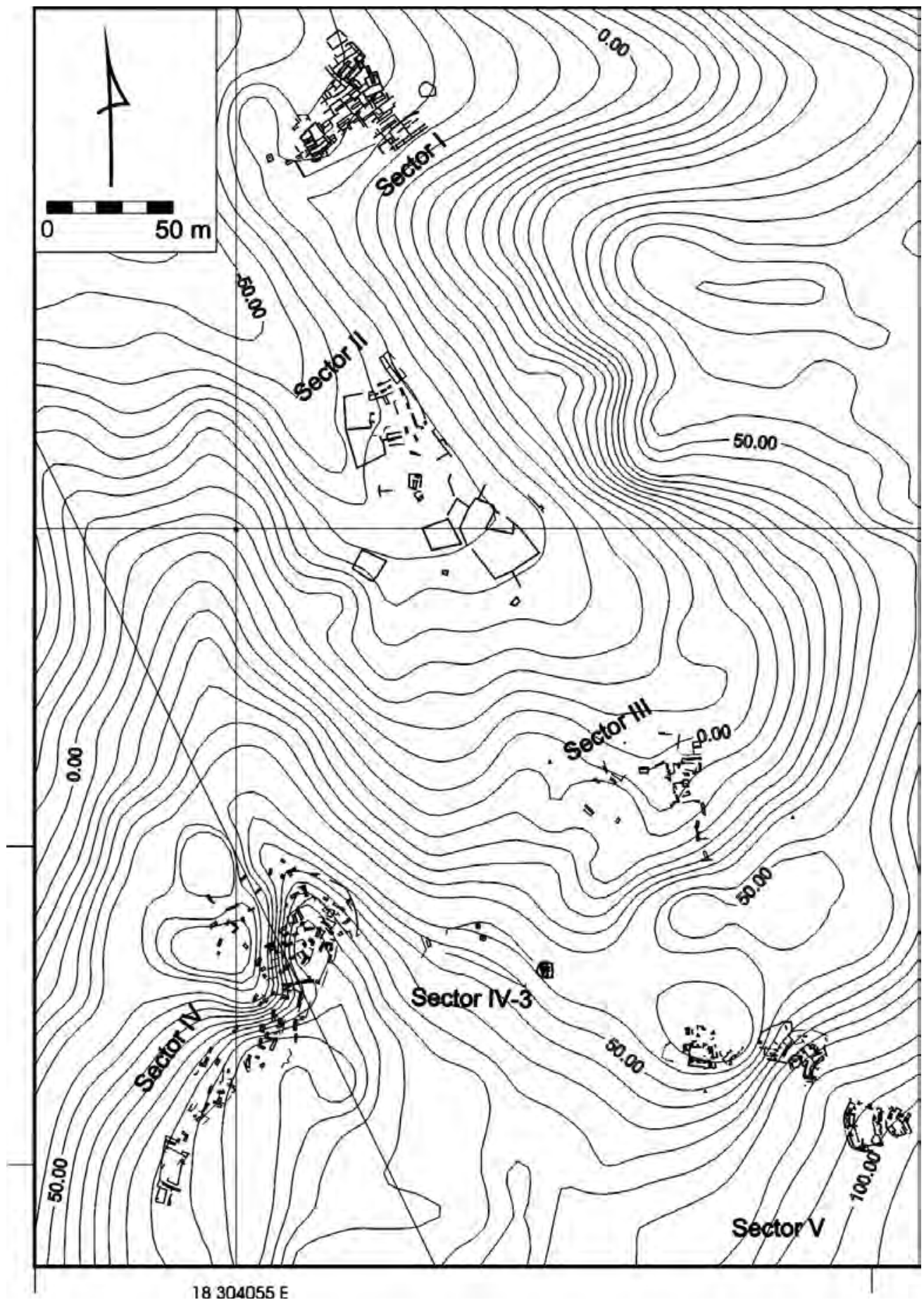

Figura 2. Plano general de Pueblo Viejo-Pucará. Obsérvese la distribución de los sectores. 


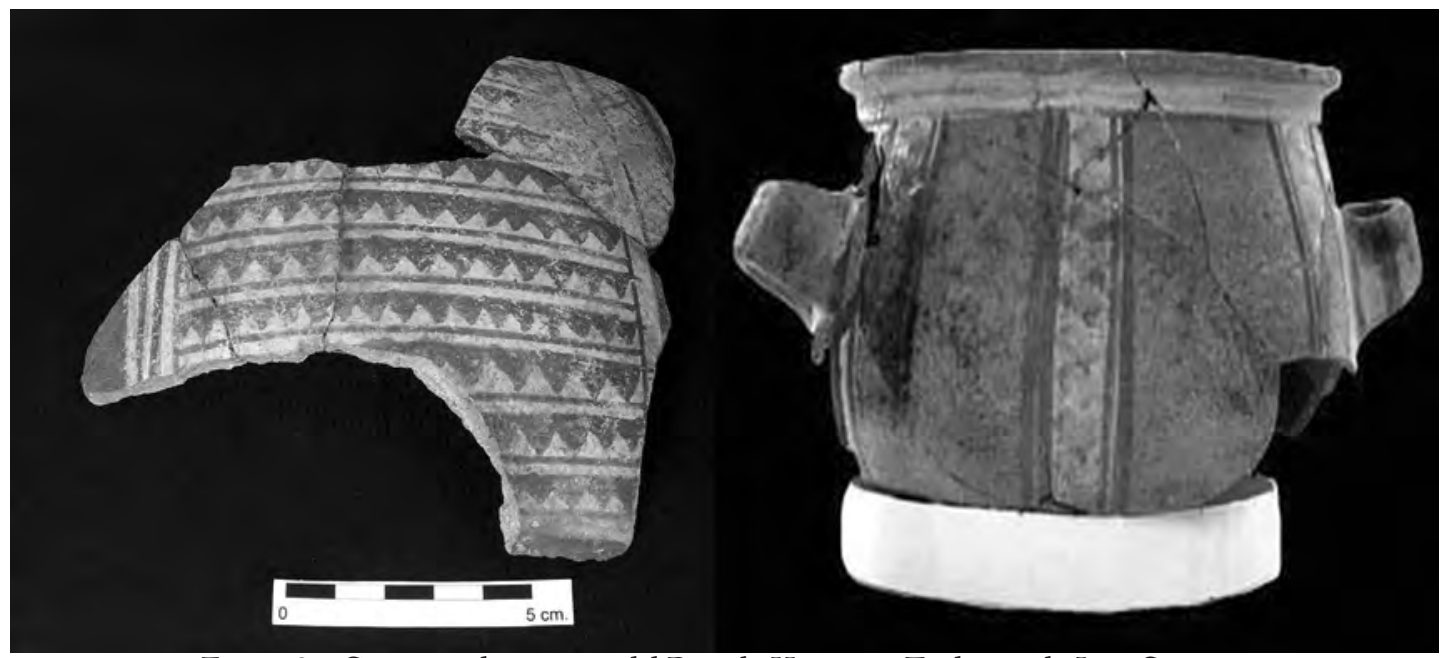

Figura 3a. Cerámica diagnóstica del Periodo Horizonte Tardío: estilo Inca Costeño.
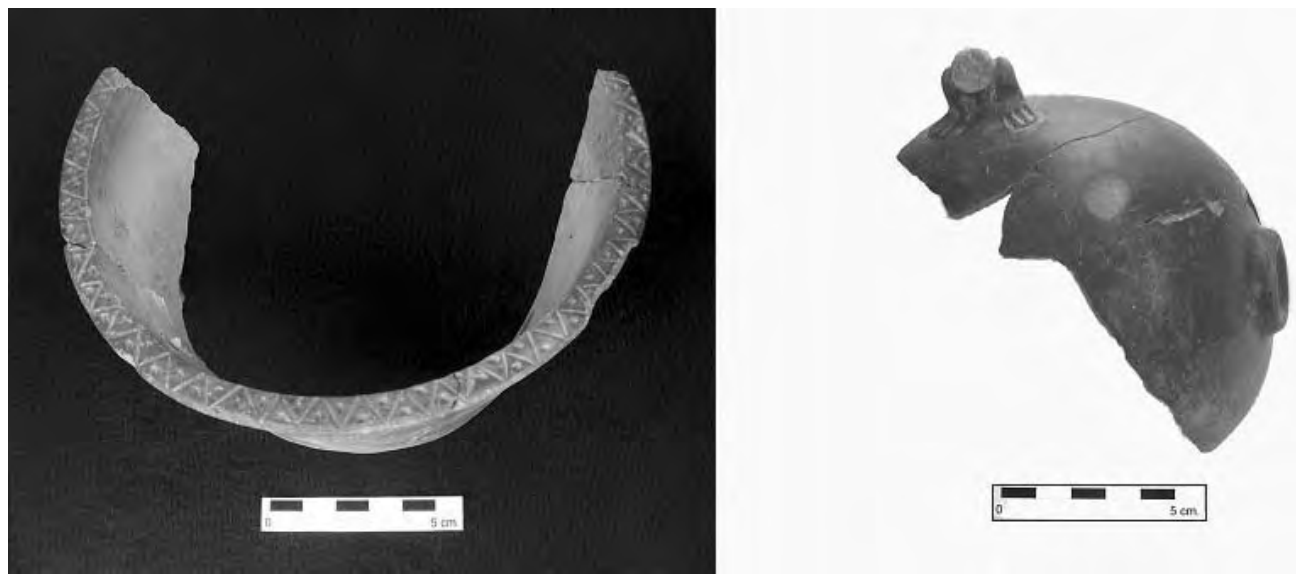

Figura 3b. Cerámica diagnóstica del Periodo Horizonte Tardío: estilo Chimú-Inca.

evidencias de material cultural relacionado a lo colonial temprano.

Así, mis investigaciones se realizaron en dos zonas distantes (sector I -mitad de abajo, y sector IV-3 - mitad de arriba) además de arquitectónicamente diferentes con la finalidad de caracterizar y contrastar las actividades en cada sector.

ARQUitectura RESIDENCIAL Y ARQUITECTURA CEREMONIAL

Dentro del sector I, se ha identificado una aglomeración de residencias de elite (fig.4) que se diferencian de las otras por la presencia del patio interno y una serie de habitaciones techadas por unidad modular, generalmente compuesta por dos depósitos alargados de dos pisos adosados a dos cuartos rectangulares paralelos. Asimismo, estas residencias de elite están compuestas por depósitos techados de dos pisos, almacenes subterráneos, dormitorios con banquetas, cocinas, cuyeras, y patios de uso común (Lizárraga 2005) (fig.5). Así, a partir de estos elementos arquitectónicos y los materiales asociados a pisos, las residencias de elite cumplieron las principales funciones domésticas como: almacenamiento 


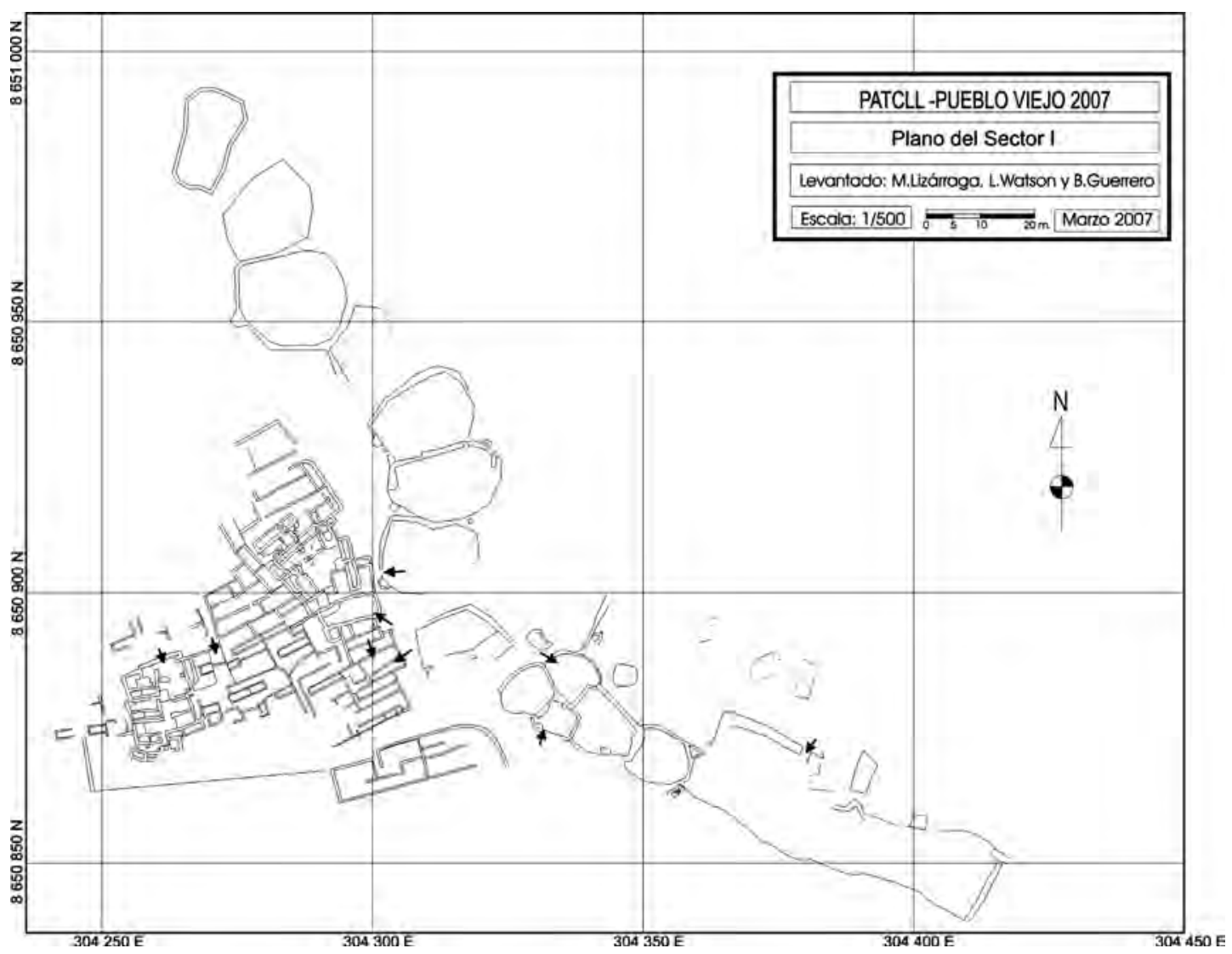

Figura 4. Plano de aglomeraciones de unidades domésticas con patio interno, Sector I.

(Dib.: M. Lizárraga, L. Watson y B. Guerrero).

de líquidos y sólidos, descanso, preparación de alimentos, crianza de animales y, eventualmente, espacios de convergencia y uso común (Kent 1990).

Sin embargo dentro de estas residencias, especialmente en los dormitorios, depósitos techados y patios; se han registrado algunas ceremonias familiares (como ofrendas, banquetes, pagos ${ }^{1}$ y entierros) durante las etapas de habitación, abandono y clausura ${ }^{2}$ de las casas, quizás como parte de la consagración del hogar (Tschopik 1968). En ese sentido, los textos de extirpación de idolatrías ( $v$ g. Ritos y tradiciones de Huarochirí) mencionan la veneración a los patios y dormitorios de las casas (Taylor 1999: 249). Del mismo modo, estudios etnográficos (Fernández 1997) registran ceremonias efectuadas por el jefe de familia en su propio hogar, incluso reportan el desplazamiento de "maestros" a las residencias vecinas para realizar "mesas", pagos y ofendas. De esta forma, las ceremonias familiares evitaban ser publicas, amenos que lo determine el oficiante o la familia (Tschopik 1968).

De este modo, las casas constituyen todo un espacio sacralizado de por sí, ya que desde su

1 Los pagos con quema ritual son una forma de sobrevalorar la ofrenda y resaltar su prestigio.

2 Datos etnográficos (Fernández 1997) informan que, las casas son clausuradas ceremonialmente para evitar la entrada de "males", amenazas externas y proteger los cultivos. 


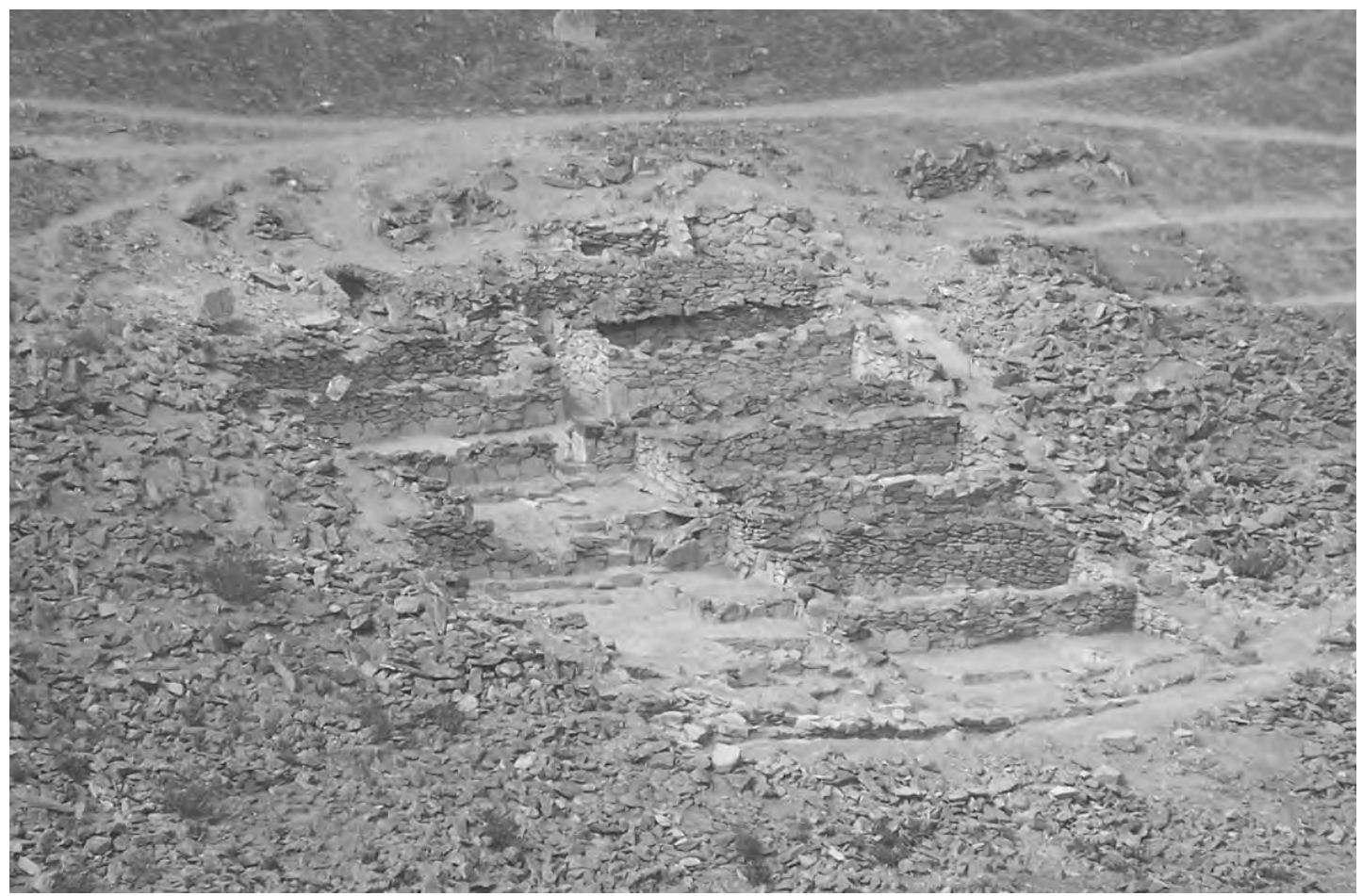

Figura 5. Residencia de elite con patio interno (Foto: M. Lizárraga).

concepción estaban envestidas de religiosidad mediante de ritos de fundación. Las reuniones públicas, que tenían lugar en el patio, no permanecían exentas de aspectos rituales (como brindis con chicha), además de manejar las relaciones políticas, como el mantenimiento de las jerarquías familiares. Efectivamente, la casa solía tener varios "espacios sagrados" de naturaleza restringida, donde el carácter ritual se desprendía de la propia funcionalidad del ambiente (es decir, de la misma cotidianidad); por ejemplo: pagos dentro de depósitos techados para proteger los productos almacenados. Por lo tanto, los residentes del sector residencial no concibieron su entorno de manera homogénea sino cualitativamente diferente, es decir, las casas (de la tradición Yauyos) estuvieron simbólicamente envueltas de connotaciones domésticas y ceremoniales. (Eliade 1967, Raymond 1994). Probablemente, estos rituales familiares se fundamentaban dentro del sistema de creencias de parentesco, tal vez en un intento por redefinir las relaciones de poder y status de los habitantes.

Por otro lado, la plataforma artificial (sector IV-3) defiere sustancialmente de los edificios que caracterizan a los complejos residenciales adyacentes (figs. 6a y 6b). La plataforma fue diseñada para ser vista desde el exterior pues aprovecha la forma natural de la cima con un muro de contención de aproximadamente $1.5 \mathrm{~m}$ de alto. Sobre la plataforma, se construyeron dos estructuras circulares distantes una de otra, las cuales son las únicas que tienen esta forma en todo el asentamiento. La más grande de ellas bordea una huaca tipo afloramiento roco$\mathrm{so}^{3}$ (fig.7a), mientras que la otra contiene una impronta circular de una posible laja vertical (ihuanca?; fig.7b); finalmente, para acceder a la

3 Promontorios rocosos trabajados y dispuestos al interior de estructuras arquitectónicas también han sido representados en varios sitios incas del valle del Cuzco (Van de Guchte 1990: Ilus. 8, "Intihuatana de Pisaq"). 


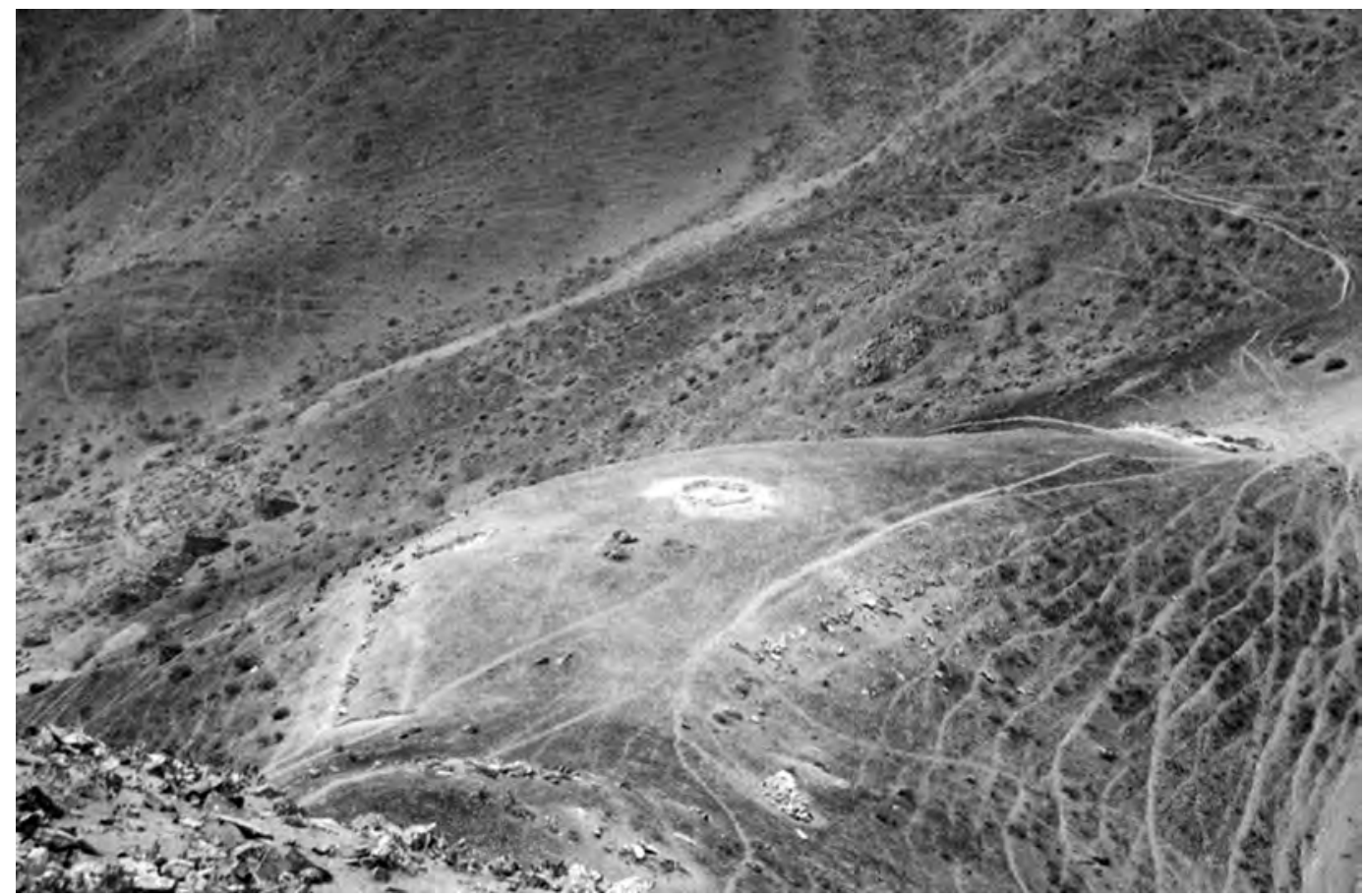

Figura 6a. Plataforma artificial, Sector IV-3, vista panorámica. (Foto: M. Lizárraga).

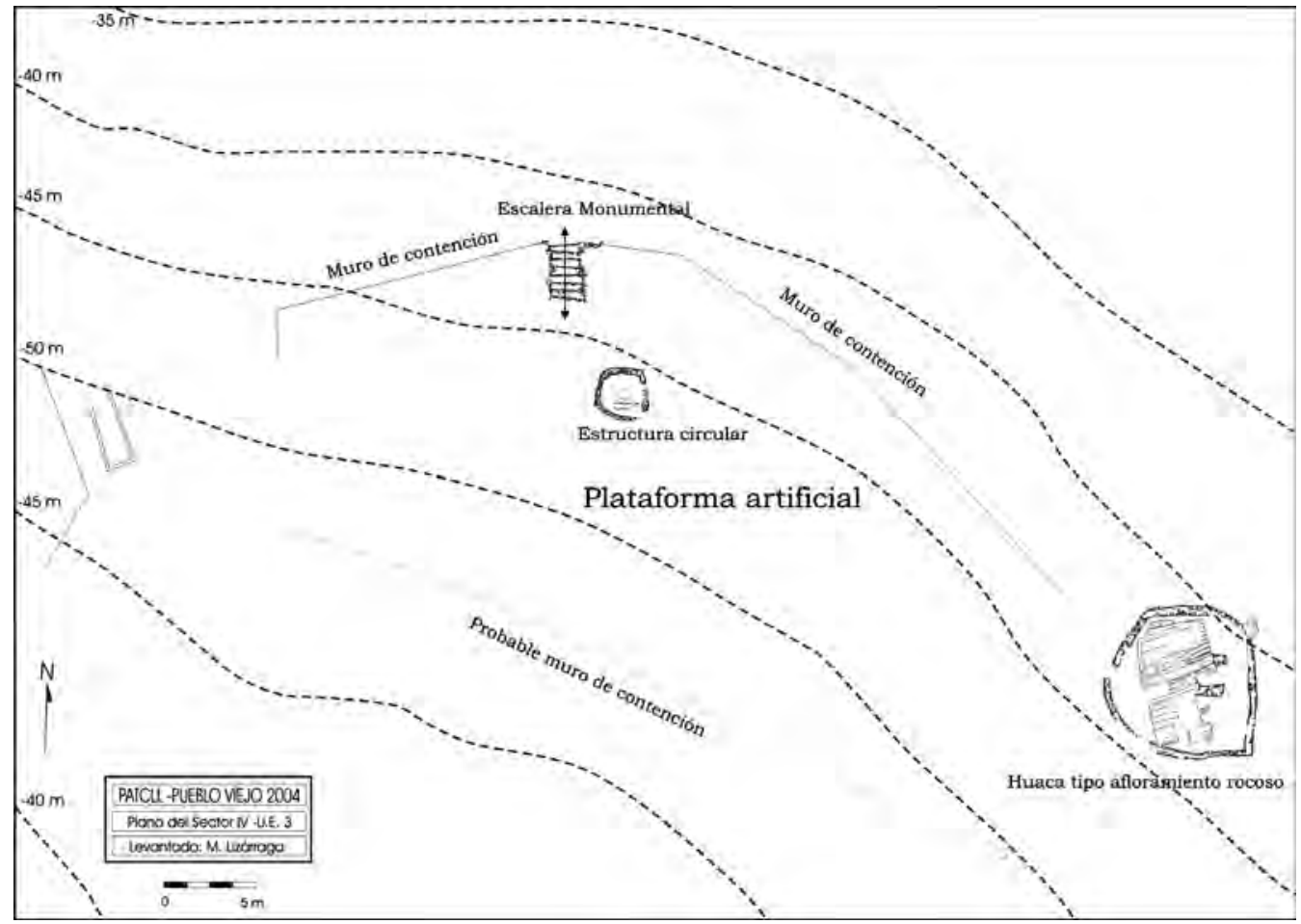

Figura 6b. Plano de la zona ceremonial (Templo de la Cima), Sector IV-3 (Dib.: M. Lizárraga). 
plataforma, se utilizaba una escalera monumental de 8 peldaños (fig.7c) (Lizárraga 2005).

Un indicio inequívoco de las actividades ceremoniales realizadas al interior del afloramiento rocoso es la presencia de ofrendas de Spondylus sp. (en fragmentos y en forma de cuentas), acompañadas de pedazos de metal trabajados dentro los nichos de la roca. Precisamente, estos elementos sagrados (vg. huanca y huaca -tipo afloramiento rocoso) se asemejan a las manifestaciones religiosas más conocidas para el mundo andino (revisar Bauer 1992, Zuidema 1989, 1995). Por lo tanto, y en base a las características mencionadas (visibilidad, ubicuidad, centralidad, escala y permanencia; Moore 1996); postulamos que la plataforma artificial funcionó como el Templo de la Cima (iachachila ${ }^{4}$, iwamami ${ }^{5}$ ), un espacio omnipresente en la zona de mayor prestigio del asentamiento, tal vez el escenario de rituales y reuniones que involucraron a toda la comunidad. Por lo tanto, el Templo de la Cima sería otro ejemplo del especial interés de los habitantes por insertar elementos culturales (construcciones e instalaciones) dentro de una armonía y correspondencia con lugares "naturales" (Kaulicke et al. 2004).

El Templo de la Cima exhibe una "lógica" ceremonial durante su visita, pues permite recorrer los distintos "altares" (vg. culto a la huanca ${ }^{6}$ y la huaca ${ }^{7}$ tipo afloramiento rocoso) dentro del orden estipulado por los oficiantes (ipertene- cientes a los ayllus de la mitad de arriba: sectores IV y V?). Estudios etnográficos (Fernández 1997) narran sobre la predilección de las cimas como lugares para realizar ofertorios, ya que representan las zonas intermedias entre los dioses y los oferentes.

\section{AsPeCTOS CEREMONIALES Y VIDA DIARIA}

Si bien las excavaciones demostraron zonas claramente para lo sagrado (Templo de la Cima) y profano (sector residencial); también pusieron en evidencia que dentro de las unidades domésticas hubo algunos eventos rituales (llamados dedicatories caches por Schiffer: 1996) como: banquetes, pozos-ofrenda ${ }^{8}$ (fig. 8), depósitos techados transformados en cámaras funerarias para recibir secuencialmente un número variado de individuos y entierros dentro de cuar$\operatorname{tos}^{9}$ (fig. 9); relacionados con la sacralización y clausura del espacio doméstico. Es probable que estas cámaras funerarias hayan sido parte del culto a los ancestros pues su ubicación, al interior de las residencias, fortalecería los lazos de parentesco entre cada uno de los residentes (Isbell 1997, Dulanto 2002).

Asimismo, en los Ritos y tradiciones de Huarochirí (Taylor 1999) se menciona que, a la muerte del jefe de familia, sus familiares limpiaban por completo la casa, para luego, organizar banquetes, bailes y sacrificios en honor al difunto. Probablemente, luego de estos rituales,

4 Protectores genéricos de las sociedades aymaras, identificados especialmente con los grandes cerros nevados de la Cordillera Oriental, considerados en las situaciones ceremoniales (Fernández 1997). Antepasado, abuelo; viejo; envejecerse; la cepa de una familia (Bertonio 1984 [1612]: segunda parte, p.5).

5 Dioses que residen en las montañas, cavernas y manantiales en las sociedades quechuas; reconocidos -familiar y comunalmente- por asegurar la reproducción exitosa de animales, cultivos y seres humanos.

6 Se define huanca, como una piedra vertical alargada, lisa o trabajada, que presenta una configuración monolítica cuya forma y tamaño puede variar, aunque frecuentemente tiene una configuración humana. Normalmente se encuentra plantada en cualquier lugar relevante a la comunidad como por ejemplo en el patio de la casa del ancestro fundador, el suelo de una chacra, en medio de corrales o en la cima de plataformas (como es el caso del sector IV-3).

7 Podemos definir el término/concepto huaca, en esencia, como aquellas manifestaciones sobrenaturales que se materializan en la naturaleza sin importar la persona, objeto, lugar u otro fenómeno de aspecto divino o inusual.

8 Cabe señalar que, la parafernalia quemada no fue necesariamente el conjunto de objetos usados por el "maestro" en su labor ceremonial sino la vajilla destinada a invitar los tragos y las comidas durante el ritual.

9 Los entierros dentro de los cuartos simbolizarían el "transito" del hombre: el individuo reingresa a la casa y la residencia se convierte en su nuevo "cuerpo" (Eliade 1967). 
las casas hayan adquirido un nuevo valor cualitativo pues ya no serían más un conjunto arquitectónico inerte sino uno con vida. De esta manera, la casa desempeña un papel fundamental en los ritos locales, como una celosa tutora de sus inquilinos (Eliade 1967, Fernández 1997).

La presencia de estos rituales familiares demostraría que entre los pobladores no existió una rígida dicotomía entre lo ceremonial/doméstico (oposición sagrado/profano como lo diría Durkheim [1912] 1993) ya que las evidencias han demostrado que lo sagrado se manifestaba en lo cotidiano. Así, un mismo ambiente residencial podía ser utilizado tanto para fines ceremoniales como domésticos, quizás en un intento de controlar lo sobrenatural desde su propio hogar. En ese sentido, necesidades domésticas como asegurar el ciclo productivo de los cultivos, proteger los recursos almacenados o mantener la casa, se convertían en los principales objetivos de las ceremonias familiares (Tschopik 1968, Flores 1977, Fernández 1997).

De otro modo, si bien el Templo de la Cima utiliza una mayor parafernalia de culto especializada (ofrendas compuestas por valvas de Spondylus sp. y pedazos de metal trabajados -fig.10) también posee vasijas (especialmente para servir y consumir alimentos) similares a las usadas dentro de las casas. Probablemente, esta vajilla sea la expresión pública de la religión comunal de "banquetes y festines políticos".

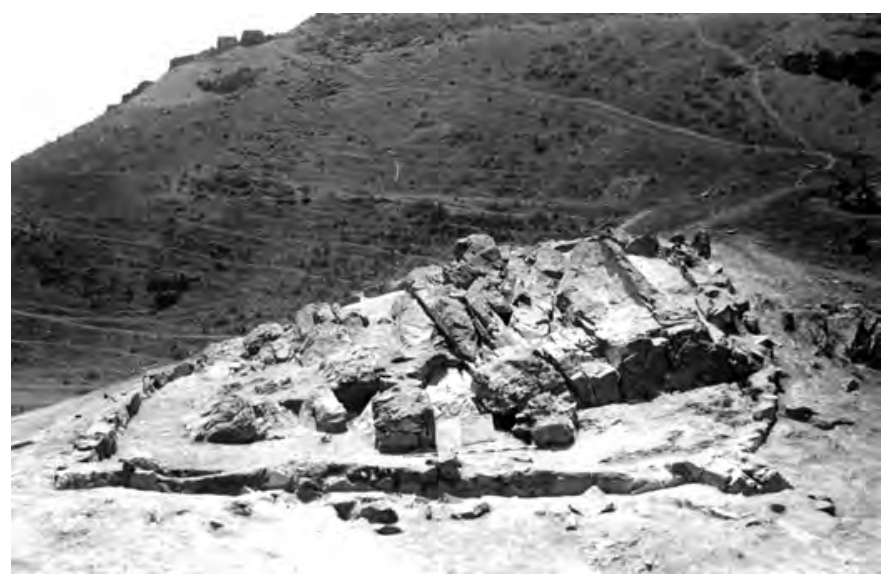

Figura 7a. Plataforma artificial, estructura circular EA-67: Huaca tipo afloramiento rocoso (Foto: M.Lizárraga).

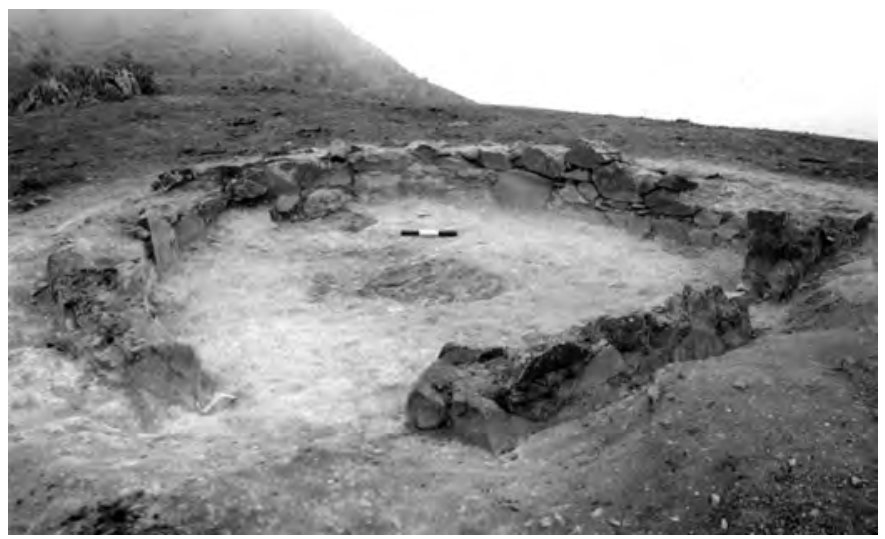

Figura 7b. Plataforma artificial, estructura circular EA-65: huella de un monolito (iHuanca?) originalmente plantado en el centro (Foto: M. Lizárraga).

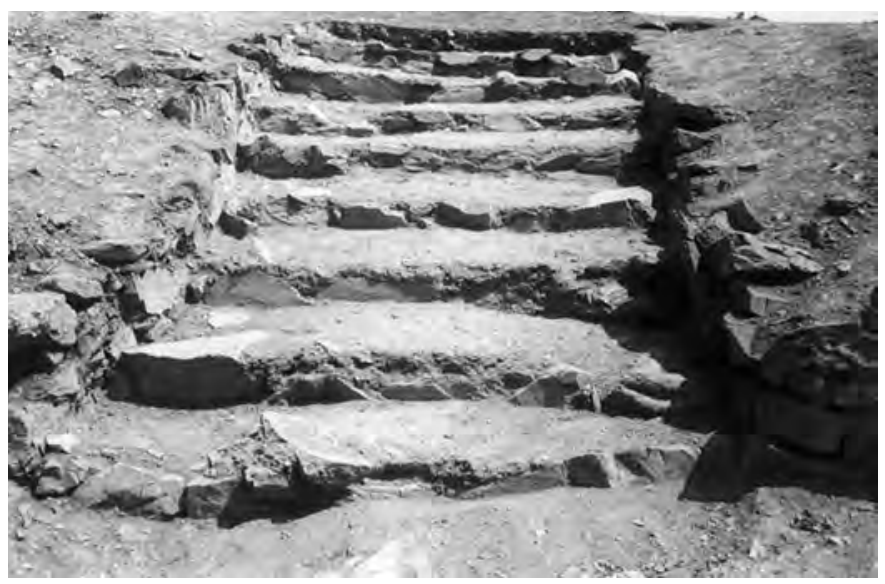

Figura 7c. Plataforma artificial, escalera monumental del acceso de la fachada Norte (Foto M. Lizárraga). 


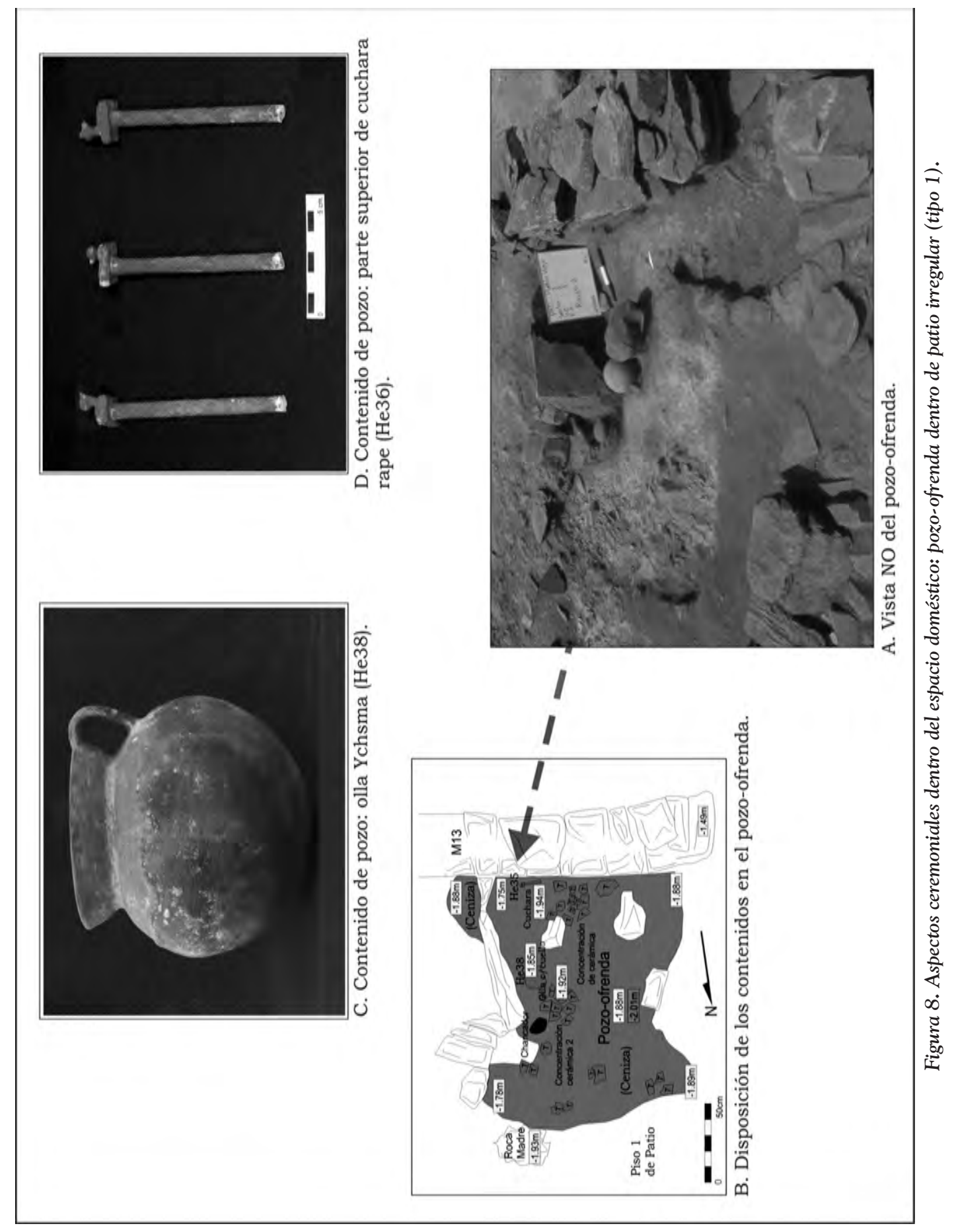




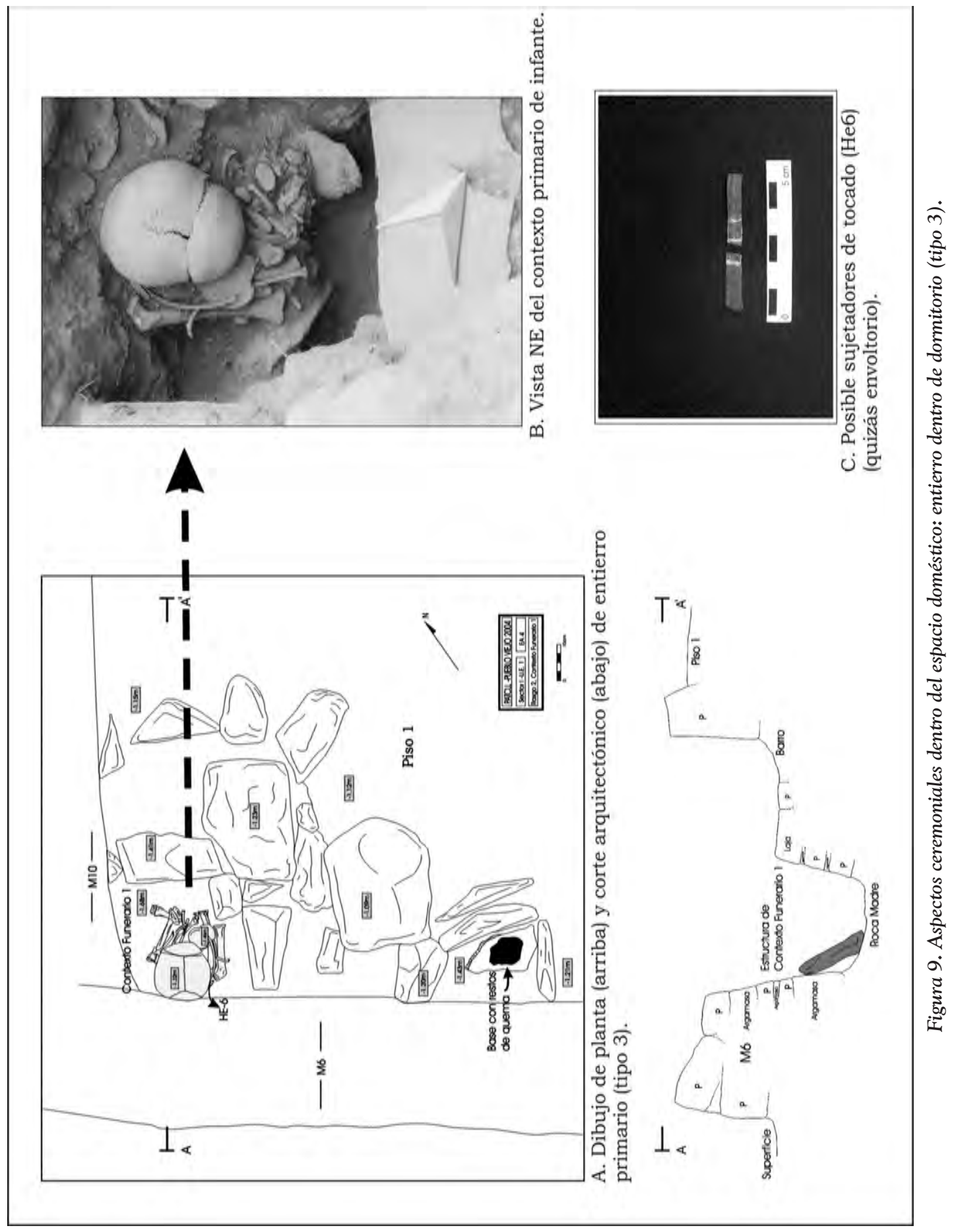




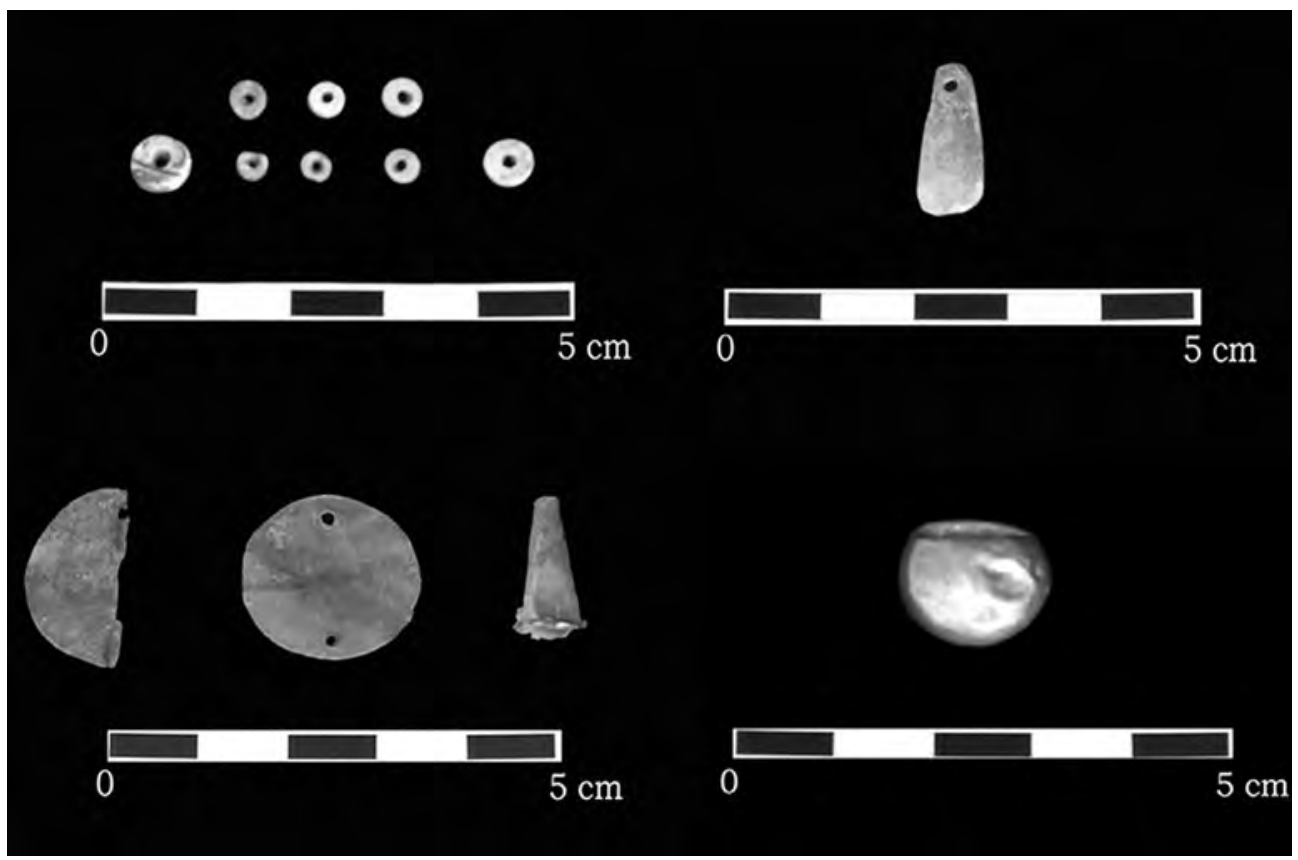

Figura 10. Parafernalia de culto especializado. Ofrendas compuestas por Spondylus sp. y pedazos de metal trabajados (Foto: M. Lizárraga).

LA OPOSICIÓN SAGRADO / PROFANO: ANÁLISIS DE LA VAJILLA RITUAL ESPECIALIZADA

Tradicionalmente se ha definido la vajilla ritual Inca como aquella compuesta por aríbalos, cuencos, botellas y vasos tipo kero de estilos Chimú-Inca (Strong y Corbett 1943) e Inca Policromo (Rowe 1944). Sin embargo, nuestros hallazgos tanto en los patios de las casas como en la plataforma artificial del Templo de la Cima revelan otro tipo de comportamiento. La vajilla recuperada en la zona ceremonial se asemeja formal y funcionalmente (fig. 11) a las vasijas para servir, consumir y preparar alimentos utilizadas en las casas del sector doméstico (sector I). Así, teniendo en cuenta la mayor demanda de vasijas para el consumo de alimentos y be- bidas, es probable que tanto en el Templo de la Cima como en los patios de las casas, se hayan desarrollado banquetes políticos y familiares, respectivamente (llamados "forced drinking10" por Wagner: 1988).

De este modo, durante las fiestas comunales, importaba comer y beber grandes cantidades de bebidas alcohólicas como parte de los "banquetes políticos ${ }^{11}$ ". Dichos banquetes eran tanto rituales como políticos pues durante las fiestas religiosas, los oficiantes consolidaban su poder mediante mecanismos de control sobre la población local; del mismo modo que los hacían partícipes de la economía colonial Inca (Dillehay 2003, Zuidema 1989). En cambio, los "banquetes familiares ${ }^{12 "}$ fueron ceremonias que

10 El concepto "forced drinking", no es un problema de alcoholismo pues ocurre esporádicamente sino, todo lo contrario, hace referencia a todo el valor ritual, religioso y político que tiene la gente para su integración social. (Wagner 1988, Zuidema 1989).

11 Los "banquetes políticos" es una manera tradicional de compartir la comida y bebida, probablemente utilizado para cimentar las lealtades y ayudar a motivar la colaboración político y militar (Dillehay 2003).

12 Los "banquetes familiares" es una celebración con rango social y ritual intrínseco que transciende la función alimentaría (Dietler 1996). 


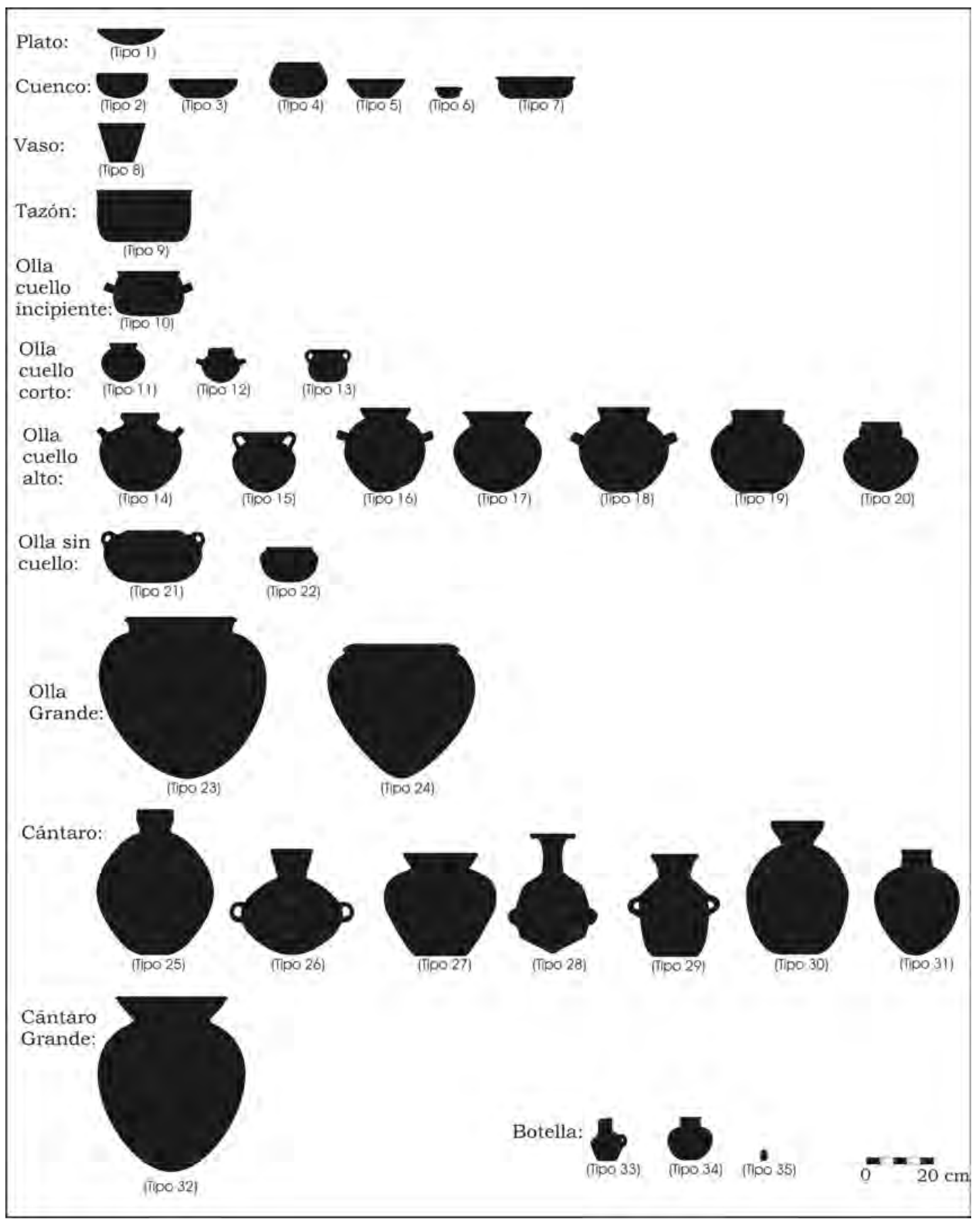

Figura 11. Principales formas del sitio Pueblo Viejo-Pucará (Dib.: M. Lizárraga). 
manipularon el status y el poder relativo entre los comensales. En ese sentido, el Padre Arriaga describe entre las ofrendas consagradas en los sacrificios de los indios de Huarochirí en el siglo XVII, lo siguiente:

La principal ofrenda, y la mejor, y la mayor parte de sus sacrificios es la chicha; por ella, y con ella comienzan todas las fiestas de las huacas, en ella median y en ella acaban sus fiestas, y ella es el todo. Y así tienen por ese efeto [sic] muchos vasos y vasijas de diferentes formas y materias (Arriaga [1621] 1999:50).

El aspecto formal es parte integral del arte ya que refleja la creatividad de los productores y usuarios (Bunzel 1972, Damp 1982). De este modo, y contrariamente a lo que se esperaba, las vasijas usadas públicamente no estaban finamente decoradas ni acabadas. Probablemente la ausencia de "vajilla de estilo imperial" (fig. 12) (vg. Inca Costeño, Chimú-Inca e Inca Serrano; Rowe 1944, Matos 2000), se deba a que éstas provengan de regiones más alejadas al valle de Lurín, quizás resultado de importaciones (como es el caso del estilo Inca importado que aparece sólo $0.15 \%$ ). De este modo, la "vajilla de estilo imperial" fue concebida como "productos de lujo", signos retóricos del dominio político del Estado Inca (Dillehay 2003), necesarios para las mediaciones sociales y políticas (comparable con el "estilo emblemático13" de Wiessner 1983).

En consecuencia, las ceremonias comunales y familiares contienen muchos de los implementos usados en la vida diaria (vasijas, herramientas líticas, etc.), por lo que no se estaría utilizando una "vajilla ceremonial" exclusiva y, más bien, sería la misma vajilla la que dependiendo de su uso y contexto, podía cumplir una doble función, sea utilitaria o ceremonial. En ese sentido, ambas colecciones pueden estar indi- cando la existencia de una "vajilla ceremonial" basada, principalmente, en formas domésticas. Es decir, tanto actividades como objetos de la vida cotidiana podían ser susceptibles de instalarse y valorarse en el plano religioso; como por ejemplo, la comida ritualizada en banquetes. De igual manera sucede en las actuales ceremonias familiares en los Andes del Sur (conocidas como "mesadas"), en donde muchos implementos usados habitualmente ( $v g$. comida, botellas y platos) también son empleados como ingredientes en las "mesas rituales" para los seres tutelares (Tschopik 1968, Fernández 1997: figura 4).

De este modo, no existe una vajilla diferenciada entre la zona ceremonial y la residencial, ni aquella usada en los rituales y actividades domésticas. Este comportamiento sugiere que muchos de los habitantes del sitio utilizaron indiscriminadamente un mismo menaje (principalmente doméstico) para realizar todo tipo de actividades, sean éstas domésticas o ceremoniales. Esto significa que no hubo necesariamente una "vasija ritual especializada14", una vajilla de prestigio reservada exclusivamente para este uso. Es probable que durante las fiestas ceremoniales lo más significativo haya sido la preparación de una "comida especial con brindis con chicha”, en donde se valoraba más los ingredientes a usar y la variedad del menú a invitar (Weismantel 1988).

\section{A MODO DE CONCLUSIÓN}

El mundo ceremonial andino está poblado por dioses y ancestros. Aunque tradicionalmente lo sagrado es visto como una manifestación restringida a determinados espacios públicos (vg. plazas, templos y plataformas artificiales; Durkheim [1912] 1993), nuestras excavaciones en el sector residencial (sector I) demostraron que

13 Estilo con fuerte carga comunicativa que define un determinado grupo social

14 En base a analogías etnoarqueológicas, DeBoer y Lathrap (1979) afirman que, la misma vajilla usada en diversas actividades domésticas (como comer, cocinar, almacenar, etc.) puede ser alterada (vg. pintada) para participar en las ceremonias familiares. 
lo sagrado y lo profano permanecieron espacialmente indivisibles, ya que muchas actividades sagradas (como ofrendas, banquetes y entierros) solían incorporarse en la vida diaria. De esta manera, las casas (de la tradición Yauyos) funcionarían como un microcosmos "abierto" a la comunicación con sus ancestros y dioses tutelares (Eliade 1967). Por otro lado, si bien la dicotomía de Durkheim [1912] (1993) puede ser relevante para algunos pocos asentamientos, la mayoría de la arquitectura en los Andes no presenta una división fundamental entre espacios sagrados y seculares (Moore 1996). Por lo tanto, cualquier espacio (público o privado) puede potencialmente alternar de significado secular a otro ceremonial, o viceversa.

Por lo tanto, en la religión andina lo sagrado estaba omnipresente y parece haber involucrado a las familias y a la comunidad por igual (Raymond 1994). Así, en base a los resultados obtenidos, se sugieren dos niveles político-ceremoniales: 1) comunal ${ }^{15}$ sobre el Templo de la Cima (iachachila?, ¿wamani?), con ritos estratificados y redistributivos para consolidar la unión del grupo; y otro 2) familiar ${ }^{16}$, al interior de las casas, con ritos participativos y recíprocos para fortalecer la unión familiar. Dichos niveles estuvieron íntimamente relacionados pues, tal como se señala en los textos de extirpación de idolatrías (Taylor 1999), muchos rituales comunales continuaban desarrollándose dentro de las residencias, convirtiendo la casa en la extensión del escenario ritual. Del mismo modo, para ambos niveles, la misma vajilla jugaba un significativo rol político envuelto de religiosidad, además de cumplir con sus propósitos cotidianos.

De esta manera, las evidencias encontradas en el sitio Pueblo Viejo -Pucará otorgan un soporte material a la abundante información antropológica sobre este tema. Las reuniones familiares y comunales buscaban el predominio político a través de lo ceremonial. Al parecer, los aspectos ceremoniales no representaban un mundo aparte sino todo lo contrario, eran considerados como parte de la vida cotidiana, en donde su existencia dependía de las obligaciones y rituales de la misma sociedad.

\section{Agradecimientos}

Este trabajo de investigación, es la versión ampliada de un tema derivado de mi tesis para optar el título de licenciado en arqueología, Pontificia Universidad Católica del Perú. Por lo tanto, deseo agradecer al Dr. K. Makowski por su apoyo, tiempo y sugerencias en este trabajo, y al Dr. S. Raymond por sus comentarios y bibliografía sobre el mundo ceremonial andino. Finalmente, a Mateo Millones y Rosabella Álvarez-Calderón por su ayuda en la redacción del mismo.

\section{REFERENCIAS}

Arriaga, Pablo Joseph de

1999 [1621] La Extirpación de la Idolatría en el Piru (1621). Cuzco: Centro de Estudios Regionales Andinos "Bartolome de la Casas".

Bauer, Brian

1992 Avances en arqueología andina. Cuzco: Centros de Estudios Regionales Andinos "Bartolomé de las Casas".

Bertonio, Ludovico

1984 [1612] Vocabulario de la lengua aymara (1612). Cochabamba: CERES, IFEA y MUSEF, Bolivia.

Bunzel, R.

1972 The Pueblo Potter. New York: Dover. Damp, Jonathan

1982 Ceramic Art and Symbolism in the Early Valdivia Community. Journal of Latin American Lore 8(2): 155-178.

15 Según los textos históricos (Arriaga [1621]1999), durante los rituales comunales se realizaban sacrificios, danzas, cantos y banquetes.

16 Los ritos familiares estaban reforzados por medio de banquetes. 
De Boer W. y Donald Lathrap

1979 "The Making and Breaking of Shipibo-Conibo Ceramics". En Ethnoarchaeology: Implications of Ethnography for Archaeology, editado por C. Kramer, pp. 103-138. New York: Columbia University Press.

Dietler, M

1996 "Feast and Commensal Politics in the Political Economy: Food, Power, and Status in Prehistoric Europe". En Food and The Status Quest: An Interdisciplinary Perspective, editado por P. Wiessner y W. Schiefenhovel, pp. 87 125. Oxford: Berghahn Books.

Dillehay, Tom

2003 "El colonialismo inka, el consumo de chicha y los festines desde una perspectiva de banquetes políticas". Boletín de Arqueología PUCP 7: 355-363.

Dulanto, Jahl

2002 "Pampa Chica: Prácticas de culto a los ancestros en la costa central del Perú". Gaceta Arqueológica Andina 26: 37-67.

Durkheim, Emile

1993 [1912] Formas elementales de la vida reliEliade, Mircea giosa. Madrid: Alianza Editorial.

1967 Lo sagrado y lo profano. Madrid: Ediciones Guadarrama.

Fernández, Gerardo

1997 Entre la repugnancia y la seducción. Ofrendas complejas en los Andes del Sur. Cuzco: Centros de Estudios Regionales Andinos "Bartolomé de las Casas".

Flores Ochoa, Jorge

1977 Pastores de Puna. Uywamichiq punarunakuna. Lima: Instituto Peruano de Estudios Andinos.

Isbell, William

1997 "Household and Ayni in the Andean
Past". En Structure, Knowledge and Representation in the Andes: Studies presented to Rainer Tom Zuidema on the Occasion of this 70th Birthday, editado por G.Urton y D.Pool, Urbana: Journal of the Steward Anthropological Society 24(1-2).

Kaulicke Peter, Ryujiro Kondo, Tetsuya Kusuda y Julinho Zapata

2003 "Agua, ancestros y arqueología del paisaje". Boletín de Arqueología PUCP 7: 27-56.

Kent, Susan

1990 Domestic Architecture and the Use of Space. Cambridge: Cambridge University Press.

Lizárraga, Manuel

2005 Aspectos ceremoniales y vida cotidiana al interior de un asentamiento urbano del Periodo Horizonte Tardío: Pueblo Viejo-Pucará, valle de Lurín, Tesis para optar por el título de licenciado en arqueología, Facultad de Letras y Ciencias Humanas de la Pontificia Universidad Católica del Perú, Lima.

Makowski, Krzysztof

2002 "Arquitectura, estilo e identidad en el Horizonte Tardío: el sitio de Pueblo Viejo-Pucará, valle de Lurin”. Boletín de Arqueología PUCP 6: 137-170.

Makowski, Krzysztof y Milena Vega-Centeno

2004 "Estilos regionales en la Costa Central en el Horizonte Tardío. Una aproximación desde el valle de Lurín". Bulletin de l'Institut Francais d'Études Andines 33(3): 681-714.

Makowski, Krzysztof, María Fé Córdova, Patricia Habetler y Manuel Lizárraga

2007 "La plaza y la fiesta: Reflexiones acerca de la función de patios en la arquitectura pública prehispánica de los periodos tardíos". Boletín de Arqueología PUCP 9, en prensa. 
Matos Mar, Ramiro

1964 "El valle de Lurín: Ambiente Físico y Cultural”. En El valle de Lurín y el pueblo de Pachacamac. Cambios Sociales y Culturales, editado por J.Matos Mar, pp.9-25. Lima: Universidad Nacional Mayor de San Marcos.

2000 "La Cerámica Inca". En Los Incas. Arte y Símbolos, editado por F. Pease, pp. 109-167. Lima: Banco de Crédito del Perú.

Millones Luis y Yoshio Onuki

1994 El mundo ceremonial andino. Lima: Editorial Horizonte.

Moore, Jerry

1996 Architecture and Power in the Ancient Andes. The Archaeology of Public Building. New Studies in Archaeology. New York: Cambridge University Press.

Raymond, Scott

1994 "La vida ceremonial en el Formativo Temprano de Ecuador". En El mundo ceremonial andino, editado por L.Millones y Y.Onuki, pp. 27-46. Lima: Editorial Horizonte.

Rowe, John

1944 "Introduction to the Archaeology of Cuzco". Papers of the Peabody Museum of American Archaeology and Ethnology. Vol.XXVII (2). Massachusetts: Harvard University.

Schiffer, Michael

1996 Formation Processes of the Archaeological Record. Utah: University of Utah Press.

Strong, William y John Corbett

1943 "A Ceramic sequence at Pachacamac. Archaeological Studies in Peru, 1941. 1942". Columbia Studies in Archaeology and Ethnology 1(2): 27-121.

Taylor, Gerald

1999 Ritos y Tradiciones de Huarochirí. Lima:
Instituto Francés de Estudios Andinos, Banco Central de Reserva del Perú y Universidad Particular Ricardo Palma.

Tschopik, Harry

1968 Magia en Chuchito. México: Instituto Indigenista Interamericano.

Vallejo, Francisco

2004 "El estilo Ychsma: Características generales, secuencia y distribución geográfica". Bulletin de l'Institut Francais d'Études Andines 33(3): 595-642.

Van De Guchte, Maarten

1990 "Carving the World": Inca monumental sculpture and landscape. Doctoral Dissertation, Department of Anthropology, University of Illinois at UrbanaChampaign, Illinois.

Wagner, Catherine

1988 Coca, chicha and trago: Private and Communal Rituals Inca Quechua Communty. Doctoral Dissertation, Department of Anthropology, University of Illinois at Urbana III, Illinois.

Weismantel, Mary

1988 Food, gender, and poverty in the Ecuadorians Andes. Philadelphia: University of Philadelphia Press.

Wiessner, Polly

1983 "Style and social information in the Kalahari San projectile point". American Antiquity 48: 253-276.

Zuidema, Tom

1989 "El Ushnu". En Reyes y guerreros: Ensayos de cultura andina, compilado por M. Burga, pp. 402-454. Lima: Fomciencias.

1995 El sistema de ceques del Cuzco: organización social de la capital de los Incas. Lima: Pontificia Universidad Católica del Perú, Fondo Editorial. 